\title{
Farklı Esansiyel Yağların Vakum Paketlenmiş ve Soğukta Depolanmış Karidesler Üzerinde Duyusal ve Kimyasal Etkileri ${ }^{\#}$
}

\author{
Süleyman ONER ${ }^{1}$, Yasemin BİRCAN YILDIRIM²*

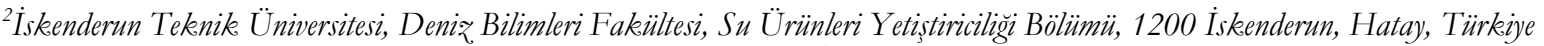 \\ ${ }^{1}$ Muğla Sıtkı Koçman Üniversitesi, Milas MYO, Otel Lokanta ve İkram Hižmetleri Bölümü, 48200, Milas, Muğla, Türkiye \\ \#Bu çalısma Mustafa Kemal Üniversitesi, Bilimsel Araştırma Projeler (BAP) birimi tarafindan desteklenen Doktora Tez Callşmamdan elde \\ edilmiștir.
}

*Corresponding author e-mail: suleymanoner@mu.edu.tr

\begin{abstract}
ÖZET
Bu çalışmada Akdeniz ve Ege sahillerimizde yaygın olarak bulunan yeşil kaplan karidesinin [Penaeus semisulcatus, (De Hann 1844)] farkl esansiyel yağ asitleriyle muamele edilerek raf ömrünün uzatılması amaçlanmıştır. Buzdolabında farklı esansiyel yağ asitleriyle muamele edilerek vakum pakette depolanan karides grupları 0.,4.,8.,12.,16.,20.,24. günlerinde kimyasal ve duyusal kalite değerlendirmeleri yapılmışır. Kimyasal değerlendirmede $\mathrm{pH}$ değerlendirmesine göre kontrol grubu 8. günde, karvakrol ile muamele edilen grup 20. günde, timol ve eugenol ile muamele edilen gruplar 24. günde, Toplam Uçucu Bazik Azot (TVB-N) değerlendirmesine göre kontrol grubu 8. günde, karvakrol grubu 16. günde, timol ve eugenol ilave edilen gruplar 20. günde ve Trimetilamin Azot Tayini (TMA-N) değerlendirmesine göre, kontrol grubu 8. günde, karvakrol grubu 16. günde, timol ve eugenol gruplarının 20. günde raf ömrünü tamamladığı belirlenmiştir. Duyusal değerlendirmede, kontrol grubu görünüş ve koku değerleri açısından 8. günde ve tat değeri açısından 4. günde raf ömrünü tamamlarken, karvakrol içeren grubun görünüş ve koku değerlerinin 20. günde, tat değerlerinin ise 16. günde raf ömrünü tamamladığı belirlenmiştir. Timol grubunun görünüş, koku ve tat bakımından raf ömrünü 24. günde tamamladığı belirlenmiştir. Eugenol grubunun duyusal değerlendirmesine bakıldığında, görünüş olarak 24, koku ve tat olarak 20. günde raf ömrünü tamamladığ belirlenmiştir. Bu duyusal değerlendirme sonuçları pH, TVB-N, TMA-N değerlendirmesi sonuçları ile paralellik göstermektedir. Timol ile muamele edilen grup duyusal olarak daha iyi olduğu için su ürünlerinin korunmasında timol kullanımı önerilmektedir. Literatür taramalarında ülkemizde karideslerde henüz böyle bir çalışmanın yapılmadığı tespit edilmiştir.
\end{abstract}

Anahtar Kelimeler: Karides, Esansiyel Yağlar, Raf ömrü

The Chemical and Sensory Effects of Different Essential Oils on Vacuum Packeged and Cold Storaged Shrimps

\begin{abstract}
The aim of this study was to increase shelf life of shrimps [Penaeus semisulcatus, (De Hann 1844)] found commonly in the mediterranean and aegean sea, by treating with different essential oils. Treated and vacuum packeged shrimp were examined as chemical and sensory within $0,4,8,12,16,20,24$, days of refrigerated storage. At the limit of the $\mathrm{pH}$ acceptability, 8. days for control, 20. for carvacrol and 24. for thymol and eugenol groups, according to Total Volatile Basic Nitrogen (TVBN) values, 8. days for control, 16. for carvacrol, 20. for thymol and eugenol groups, regarding to Trimethylamine-Nitrogen (TMAN) values, 8.days for control, 16 . for carvacrol, 20. for tymole and eugenol groups were completed the shelf life. The control extended the shelf life 8 . for appearance and odor, 4. days for taste. Carvacrol group reached the shelf life 20. for apparence and odor, 16. for taste evaluation. The shelf life of eugenol group was at 24. for apparence, odor and 20. days for taste. In the respect to apperance and odor, taste, the tymole used group completed shelf life at 24 . days. The result of sensory evaluation showed the similar shelf life related days with pH, TVBN, TMAN values. Tymole was advised for consumer due to higher sensory evaluation. It has been determined that there was not a study like this one on shrimp at literature in Turkey.
\end{abstract}

Keywords: Shrimp, Essential oils, Shelf life

To cite this article: Oner S. Yuldurm Y.B. Farkh Esansiyel Yağlarn Vakum Paketlenmiş ve Soğukta Depolanmıs Karidesler Üzerinde Duyusal ve Kimyasal Etkileri. Kocatepe Vet J. (2018) 11(4): 472-478. 


\section{GİRİŞ}

Türkiye denizlerinde bugüne kadar 60'1n üzerinde karides türü saptanmış olup, bunlardan 7'sinin ticari olarak avcıllı̆ı yapılmaktadır. Bu türlerden Penaeus semisulcatus, Metapenaeus monoceros Kiz1l Deniz kökenli olup, Akdeniz ve Ege sahillerimizde yaygin olarak bulunur (Kocataş ve ark. 2004, Can ve ark. 2006).Avlandiktan sonra k1sa sürede bozulabilen karideslerin hemen işlenmeleri ya da dondurularak muhafazaya alınmaları gerekmektedir (Ünlüsayın ve Gülyavuz 2008). Diğer taraftan, uzun süreden beri, besinlerin koku ve tat gibi özelliklerini arttırmak için katkı maddesi olarak kullanılan baharat ve doğal aromatik bitkilerin kullanımı giderek önem kazanmaktadır. Gidaların taze olarak muhafaza edilebilmesi için doğal katkı maddeleri olarak, esansiyel yağların kullanımı yaygınlaşmıştır (Fernandez-Lopez ve ark. 2005). Yapilan çalışmalarda, esansiyel yağlarla muamele yapılması ve vakum paketlemesi sonucu su ürünlerinin raf ömrünü arttırmada iyi sonuçlar alınmıştır (Karaman ve ark. 2001, Kykkidou ve ark. 2009, Frangos ve ark. 2010, Mastromatteo ve ark. 2010). Çalışmada kullanılan esansiyel yağlardan Timol (C10H14O) 5methyl-2- isopropylphenol olarak adlandirlir ve monoterpenler grubuna aittir (Lambert ve ark.2001). Kimyasal yap1 olarak, 2-methyl-5-1methylethyl phenol olarak adlandirılan karvakrol monoterpenik bir fenoldür (Lee ve Jin 2008). Eugenol ile ilgili olarak yapılan bir çalışmada karanfilin güçlü antioksidatif etki gösterdiği ortaya konmuştur (Lean ve Suhaila 1999). Bu çalışmanın amacı farklı esansiyel yağların vakum paketlenmiş ve soğukta depolanmış karidesler üzerinde duyusal ve kimyasal etkileri araştırılmasıdır.

\section{MATERYAL ve METOT}

Yapılan mevcut çalışmamızda; kekikten elde edilen karvakrol, timol ve karanfilden elde edilen eugenol esansiyel yağlarının \%1 oranındaki çözeltisi, İskenderun Körfezi'nde avlanan Penaeus semisulcatus türü karideslere muamele edilmiş, vakum pakette $+4^{\circ}$ C'de 24 gün depolanmış ve bu süre boyunca kimyasal, duyusal parametrelerine bakılarak raf ömrü incelenmiştir. Trol ağlariyla avlanan karidesler İskenderun Balıkçı Barınağı'ndan sulu buz dolu strafor kutular içerisinde laboratuvara ulaştırılmıştır. Araştırmada timol (Sigma Aldrich T0501), karvakrol (Sigma Aldrich 282197) ve eugenol (Sigma Aldrich E51791) esansiyel yağları $\% 1$ oranında kullanılmıștır. Mustafa Kemal Üniversitesi Veteriner Fakültesi Besin Hijyeni ve Teknolojisi Laboratuarına getirilen karideslerin ortalama 13-18 cm boyunda ve 30-50 g ağırlığında olduğu tespit edilmiştir. Çalışmamızda I. grup; \%1 timol, II. grup; \%1 karvakrol, III. grup; \%1 eugenol uygulanan gruplar, IV. grup ise kontrol olarak belirlenmiştir. Çalışmamızda kontrol grubu ve esansiyel yağlarla muamele edilmiş gruplar hazırlanırken, her bir paket karides, $100 \mathrm{~g}$ lik olacak şekilde polyamid bazlı vakum poşetleri içine yerleştirilmiş ve vakum makinesi (Laica SPAViale del Lavaro, 1036020 Barbarano- VicenzaItaly) kullanilarak vakum paketleme yapılmıştır. Vakum paketlenen örnekler buzdolabı ortaminda homojen olarak yerleştirilmiş ve depolanmıştır. Tüm analizler iki paralelli ve üç tekerrürlü olarak yapılmıştır. Çalışmada elde edilen veriler her analiz gününde her bir grup için üç paket karides filetosu kullanılarak elde edilmiştir. 0., 4., 8., 12., 16., 20., 24. günlerde duyusal, kimyasal analizler yapılmıştır. $\mathrm{pH}$ ölçümü Santos ve ark. (1981), Toplam Uçucu Bazik Azot (TVB-N) analizi Antonacopoulos (1973), Trimetilamin Azot Tayini (TMA-N) ise Boland v e Paige (1971)'e göre yapılmıştır. Duyusal analiz değerlendirmesi (Neuman ve ark. 1985, Varlik ve ark. 1993a) göre yapılmıştır (Çizelge.1). Varlık ve ark. (1993a)'na göre duyusal analiz puanlamasinda 3 ile 4 arası puan alan su ürünleri örnekleri "Kötü" olarak değerlendirilmiştir. Ürünün duyusal değerlendirilmesinde Mustafa Kemal Üniversitesi öğretim üyeleri ve lisansüstü öğrencilerinden oluşan, daha önce bu tür çalışmalara katılmış olan tecrübeli 5 panelist görev almıştır. Karides etleri çiğ ve pişmiş şekilde tabaklarda panelistlere sunulmuştur. Duyusal analiz için ürünün renk, koku, tat, ve genel kabul edilebilirlik kriterleri baz alınarak 0- 9 aralığında değerlendirilmiştir. Ayrıca karides etinin duyusal analizlerinde numuneler pişirme denemeleri ile incelenmiştir. Pişirme denemelerinde ağz1 kapaklı kaplara konulan karides 10 dakika süre ile $90 \pm 3^{\circ} \mathrm{C}^{\prime} \mathrm{de}$ su banyosunda tutularak, muamelelerde renk, koku ve tat kabul edilebilirlik dereceleri tespit edilmeye çalışılmıştır.

\section{İstatistiki Analizler}

Standart sapma ve korelasyon varyasyonu için, her bir depolama günü ve muamele gruplarinın üç tekrarlı olarak karşılaştırması yapılmıştır. Kimyasal analizlerin sonuçlarina SPSS 16.00 istatistik programinda Duncan çoklu karşılaştırma testi uygulanmiştır. Duyusal analiz sonucu elde edilen veriler SPSS istatistik paket programinda nonparametrik bir test olan "Kruskal-Wallis" ve Duncan çoklu karşılaştırma yöntemine göre yapilmıştır.

\section{BULGULAR ve TARTIŞMA}

Depolama süresi boyunca pH değeri 6.81 ile 8.67 arasında değişim göstermiştir. Tüm gruplarda depolama süresince $\mathrm{pH}$ değerinde istatistiksel olarak önemli farklılıklar görülmüştür (Şekil. 1). Shamshad ve ark. (1990a) belirlediği pH bozulma 
limiti 7,95 değeri olup, kontrol grubu bu değeri 8 . günde (7.96), karvakrol ile muamele edilen grup 20. günde (8.17), timol uygulanan grup 24. günde (8.37) ve eugenol uygulanan grup ise $8.34 \mathrm{pH}$ değeri ile bozulma limitini 24. günde aşarak raf ömrünü tamamlamışlardır. Şentürk (1994) taze karidesin pH'sının yaklaşık 7-7.2 arasında olduğunu, $\mathrm{pH}^{\prime}$ in depolama süresince artarak kokuşma evresinde 8.2'ye kadar yükseldiğini bildirmiştir. Varlık ve ark. (2000) ise taze karideslerin $\mathrm{pH}$ değerinin 6,73 olduğunu $4^{\circ} \mathrm{C}$ 'deki karideslerin ise 4.üncü günde 7,81'e yükseldiğini ifade etmişlerdir. Bilgin ve Erdem (2006), karideslerin [Crangon crangon (Linnaeus, 1758)] $\mathrm{pH}$ değerini pişmiş karideslerde deneme başında

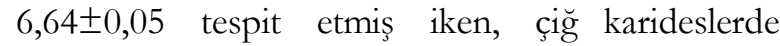

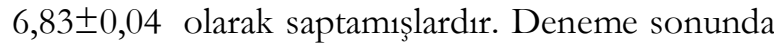
(5.gün) ise, pişmiş karideslerde $\mathrm{pH}$ 7,77士0,05

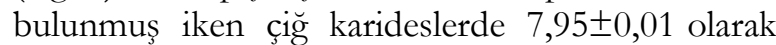
belirlenmiștir. Muhafaza süresince artışların istatistiki olarak önemli olduğunu bulmuşlardır. Çalışmamızda elde edilen $\mathrm{pH}$ değeri raf ömrü sonlanma günü değerlendirmesine göre Shamshad ve ark. (1990b), Varlik ve ark. (2000), Erdem ve Bilgin (2004)'nın çalışma sonuçlarına benzerlik göstermektedir. Huss (1988), balik ve su ürünlerinin TVB-N değeri, $35 \mathrm{mg} / 100 \mathrm{~g}^{1}$ aştı̆̆ında "Bozulmuş" olarak tanimlamıștır. Buna göre çalışmamızda kontrol grubu 8. günde 58.09 $\mathrm{mg} / 100 \mathrm{~g}$, karvakrol uygulanan grup 16. günde $35.24 \mathrm{mg} / 100 \mathrm{~g}$, timol ile muamele edilen grup 20 . günde $43.86 \mathrm{mg} / 100 \mathrm{~g}$, eugenol uygulanan grup ise 20. günde $42.44 \mathrm{mg} / 100 \mathrm{~g}$ TVB-N miktarı ile kritik limit değeri olarak baz alınan 35 mg/100g’1 aşmıştır. Çalışmamızda kontrol grubunda karides etinin başlangıç TVB-N değeri 8,24 mg/100g olarak bulunmuştur. Başlangıç TVB-N değerleri tüm gruplarda birbirine yakın olmasina rağmen, uygulanan esansiyel yağ çeşidine göre depolama sürecinde önemli değişiklik göstermiştir (Şekil.2). Gruplar arasında TVB-N bakımindan istatistiksel olarak önemli farkliliklar bulunmuştur. Çalışmamızda bulunan sonuçlar Chang ve ark. (1983)'nın çalışması ile benzerlik göstermektedir. Diğer çalışmalarla, (Stockemer ve Niger 1984, Shamshad ve ark.1990b) çalışmamızdaki, TVB-N değeri farkının, çeşitli su ürünlerinin cinsi, avlanma mevsimi, olgunluk derecesi, cinsiyeti ve yaşı gibi faktörlerden kaynaklandığ1 düşünülmektedir. Literatür taramalarında ülkemizde karideslerde henüz böyle bir çalışmanın yapılmadığ tespit edilmiştir. Çalışmamızda taze karides başlang1ç TMA-N değeri $0.93 \pm 0.03 \mathrm{mg} / 100 \mathrm{~g}$ olarak bulunmuştur. Depolama süresince TMA-N değerinde önemli artışlar gözlenmiştir (Şekil.3). Uygulama gruplarının kendi aralarında ve günler aras1 istatistiksel olarak farklılıklar gözlenmiştir. Varlık ve ark. (1993b) tüketime uygun su ürünlerinde TMA-N değerinin 1-8 mg/100g olduğunu, $8 \mathrm{mg} / 100 \mathrm{~g}$ TMA-N değerinin ise bozulmuşluğu belirlediğini saptadıklarını bildirmişlerdir. $8 \mathrm{mg} / 100 \mathrm{~g}$ TMA-N değeri bozulma kriteri olarak ele alındığında, çalışmamızda kontrol grubu 8 . günde $8.30 \mathrm{mg} / 100 \mathrm{~g}$, karvakrol ile muamele edilen grup 16. günde $8.18 \mathrm{mg} / 100 \mathrm{~g}$, timol uygulanan grup 20. günde $8.33 \mathrm{mg} / 100 \mathrm{~g}$ ve eugenol uygulanan grup ise 20. günde 8.21 $\mathrm{mg} / 100 \mathrm{~g}$ ile bu limit değeri aşmıs olup raf ömrünü tamamlamıstır. TMA-N sonuçlarının, pH, TVB-N değerlerinin benzerlik göstermesi, kimyasal değişim parametrelerin raf ömrünü belirlemede birbirini doğrulayıc1 olduğunu göstermektedir. Çalışmamızda bulunan sonuçlar, Varlık ve ark.1993b, Stockemer ve Nieper. (1984), Bilgin ve ark. (2006)'nın çalışma sonuçları ile benzerlik göstermektedir. Çalışmamız, karides etlerinin esansiyel yağ asitleriyle muamele edilmesi, vakum paketlenmesi ve soğukta depolanarak kimyasal ve duyusal değişimlerin gözlemlenmesiyle, Ülkemizde şimdiye kadar yapılan benzer çalışmalardan ayrılmaktadır. Çalışmamızda başlangıçta yüksek olan duyusal değerler zamanla azalma göstermiş ve 4 puanın altına düştüğünde kötü ve duyusal olarak kabul edilemez olarak puanlanmıştır. Buna göre kontrol grubu görünüş açısından 3.82 ve koku 3.52 puan alarak 8. günde ve tat olarak 4. günde 3.70 puanla raf ömrünü tamamlamıştır. Karvakrol uygulanan grup ise görünüş 3.79 ve koku 3.96 puanla 20. günde, tat değerlerine bakıldığında ise 16. günde 3.78 puanla raf ömrünü tamamlamıştır. Timol ile muamele edilen grup ise görünüş 3.87, koku 3.76 ve tat 3.92 puanla raf ömrünü 24 . günde tamamlamıştır. Eugenol uygulanan grup ise duyusal değerlendirmeye bakıldığında görünüş 3.40 olarak 24. günde, koku 3.56 ve tat 3.64 puanla 20 . günde raf ömrünü tamamlamıştır (Şekil.4, Şekil.5, Şekil.6, Şekil.7). Bu duyusal değerlendirme sonuçları $\mathrm{pH}$, TVB-N değerleri ile raf ömrü tamamlama günleri bakımından benzerlik göstermektedir.

Erdem ve Bilgin (2004)'in çalışmasında duyusal bulgulara göre $4^{\circ} \mathrm{C} \pm 1$ 'de muhafaza edilen pişmiş karidesler 3 gün, çiğ karidesler ise 2 gün tazeliklerini korumuşlardır. Matches (1982)'a göre 5,6 ${ }^{\circ} \mathrm{C}$ 'de karideslerin duyusal açıdan 6 . güne kadar tüketilebilir düzeyde olduğu belirtilmiştir. Varlık ve ark. (2000)'a göre $4^{\circ} \mathrm{C} \pm 1$ 'de muhafaza ettikleri karideslerin, duyusal olarak 2. günde bozuldukları belirlenmiştir. Stockemer ve Nieper (1984) $7^{\circ} \mathrm{C}$ de depolanan karideslerin, duyusal değerlere göre tüketilebilir sınır değerini 4. günde aştı̆̆ını bildirmişlerdir. Literatür verileriyle bulgularımız arasında bazı farklılıkların bulunmasının, incelenen karides türü ve muhafaza koşullarından (vakum paketleme, esansiyel yağ asitlerle muamele) kaynaklandığı sonucuna varılmıştır. 
Çizelge 1. Duyusal analiz d eğerlendirme formu (Neuman ve ark., 1985., Varlık ve ark., 1993a).

Table 1. Sensory Evaluation Form (Neuman and et al., 1985., Varlik and et al., 1993a).

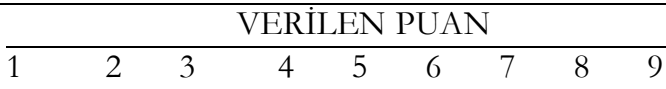

\section{GÖRÜNÜŞ}

Etin rengi beyazımsı, soluk beyaz yada çok hafif bir renklenme

Değişik (hafif) tonlarda grimsi

Kuvvetli renklenme

\section{KOKU}

Hoş, spesifik

Yavan, tatsız, bayat

Balıksı, ağır

Kötü koku

Keskin kötü koku, amonyağımsı

\section{TAT}

Çok iyi, spesifik-aromatik

İyi

Orta

Balıksı, nahoș, hafif acı

Kuvvetli balığımsı, acı

Kuvvetli balığımsı, acı

Çok kötü, iğrenç

Genel Kabul Edilebilirlik

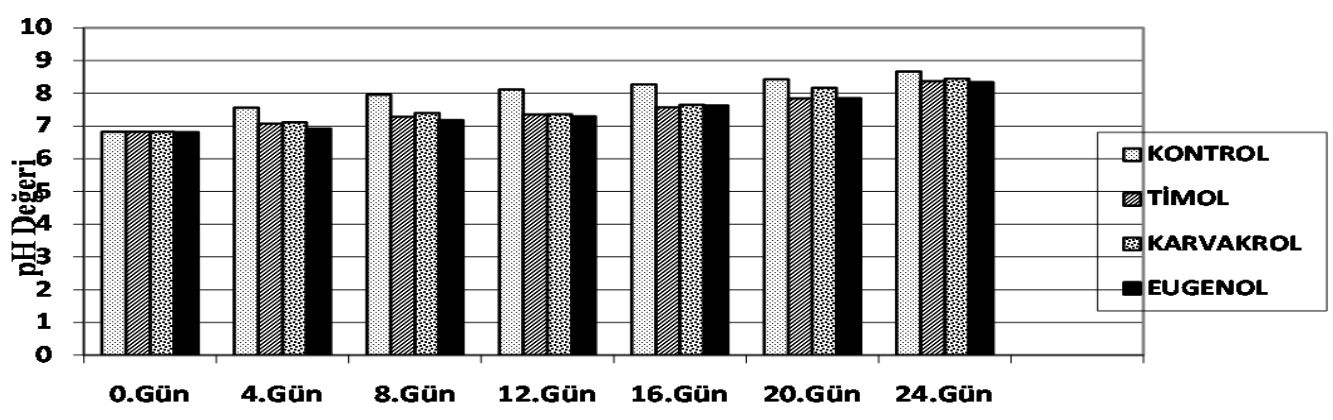

Şekil 1. Buzdolabında depolama boyunca karides etinde $\mathrm{pH}$ değişimi

Figure 1. $\mathrm{pH}$ values variation during refrigerated storage

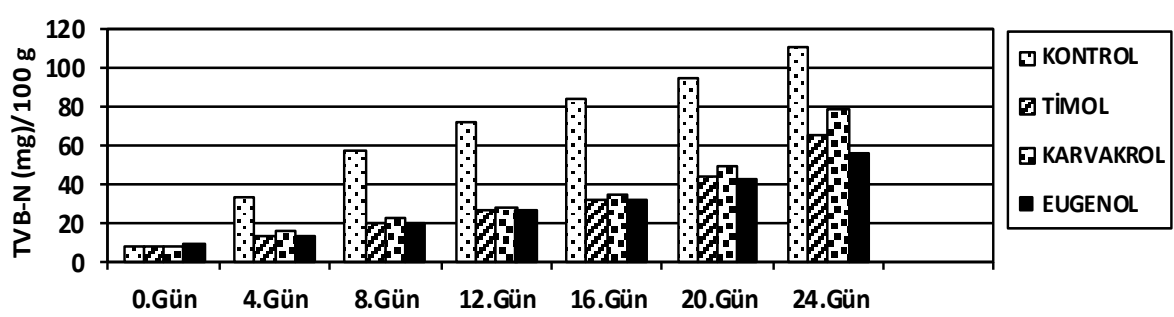

Şekil 2. Buzdolabında Depolama boyunca karides etinde TVB-N Değişimi

Figure 2. TVB-N values variation during refrigerated storage 


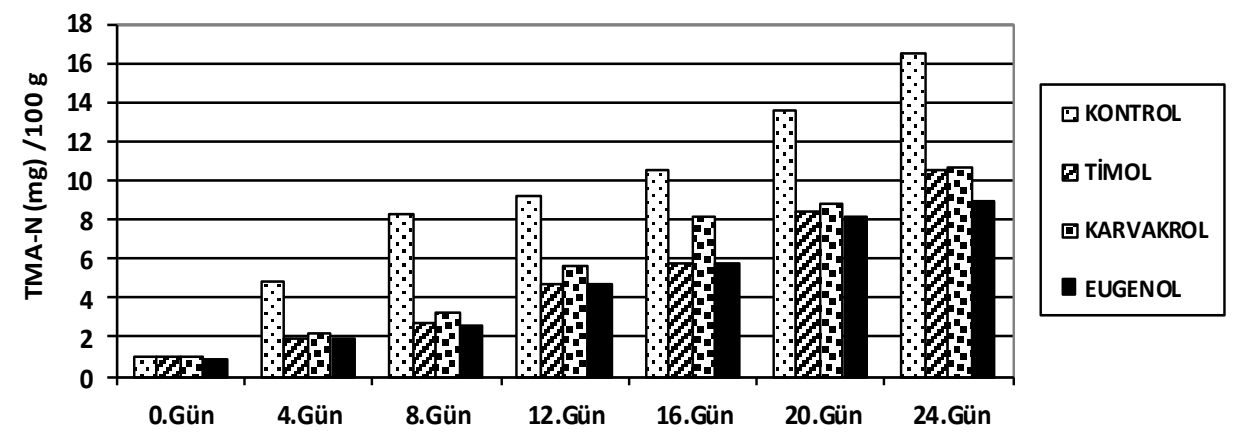

Şekil 3. Buzdolabında Depolama boyunca karides etinde TMA-N miktarındaki değişiklikler

Figure 3. TMA-N values variation during refrigerated storage

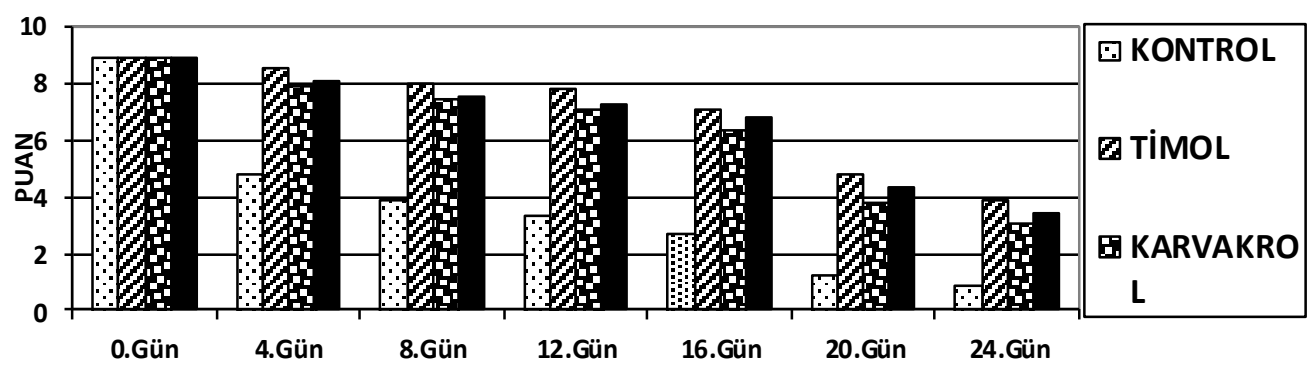

Şekil 4. Buzdolabında Depolama boyunca karides etinde görünüş testi değerindeki değişimler

Figure 4. Apperance values variation during refrigerated storage

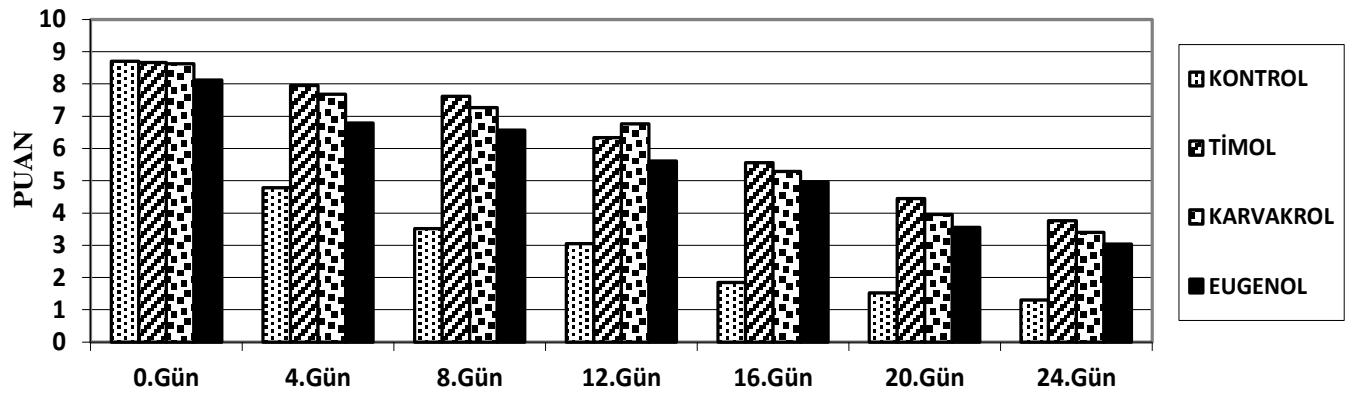

Şekil 5. Buzdolabında Depolama boyunca karides etinde koku testi değerindeki değişimler Figure 5. Odor values variation during refrigerated storage 


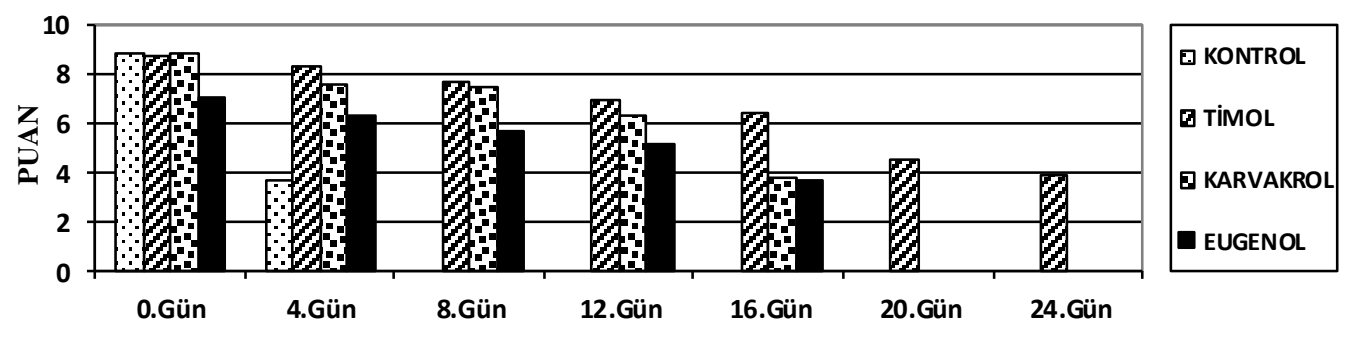

Şekil 6. Buzdolabında Depolama boyunca karides etinde tat testi değerindeki değişimler

Figure 6. Taste values variation during refrigerated storage

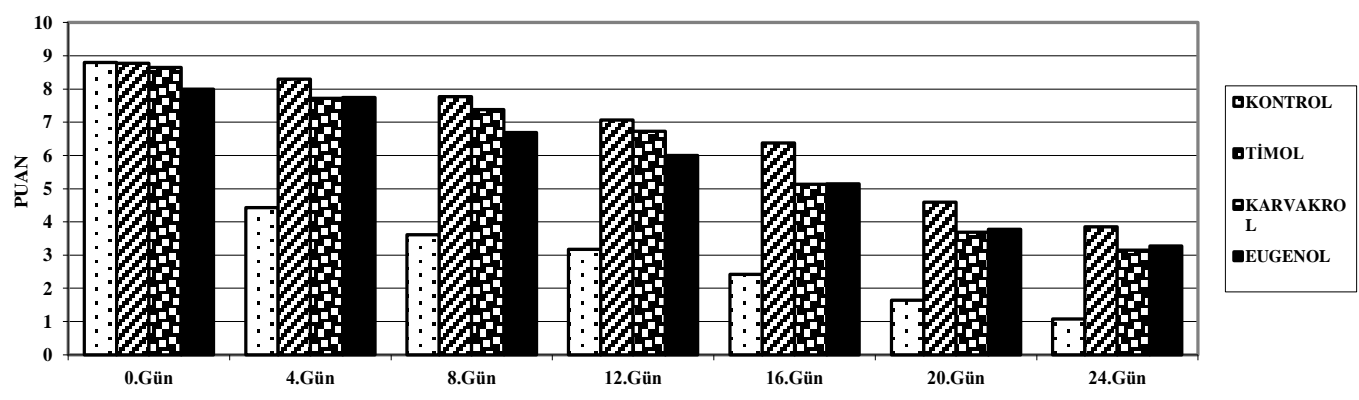

Şekil 7. Buzdolabında Depolama boyunca karides etinde oluşan genel kabul edilirlik

Figure 7. General acceptability values variation during refrigerated storage

\section{SONUÇ}

Duyusal değerlendirme sonuçları $\mathrm{pH}$, TVB-N, TMA-N değerlendirmesi ile paralellik göstermektedir. Kimyasal parametrelere bakıldığında raf ömrü açısından eugenol uygulanan grup her ne kadar uzun raf ömrü sağlamış olsada timol uygulaması duyusal olarak ve ürünlerin satıs imkânları açısından daha iyi olduğu için, timol uygulamasının, su ürünlerinde raf ömrünü arttırmak için esansiyel yağ uygulaması olarak tercih edilebilir olduğu görülmüştür. Daha ileride yapılacak çalışmalarda, farklı gaz oranlarını içeren paketleme ve farklı dozları kapsayan her yörenin kendi damak tadına yakın olan esansiyel yağ kullanılarak ve daha düşük sicaklık derecesinde daha uzun süreli mevsimsel değişimleri içerecek şekilde denemeler yapılabilir.

\section{KAYNAKLAR}

Antonacopoulos N. Comparison of Sensory and Objective Methods for Quality Evaluation of Fresh and Frozen Saltwater Fish. Fish Inspection and Qulity Control. Fishing New Books. 1973.;80- 181.

Bilgin S, Erdem ME ve Duyar HA. Pişmiş ve Çiğ Olarak Buzdolabı Sıcaklığında Muhafaza Edilen Kahverengi Karides'in, Crangon Crangon (Linnaeus, 1758), Kimyasal Kalite
Değişimleri. Firat Üniv. Fen ve Müh. Bil. Der. 2006;18 (2): 171-179.

Boland FE and Paige DD. Collaborative Study of a Method for the Determination of Trimethylamine Nitrogen in Fish. Jour. of the AOAC. 1971; 4 (3): 725-727.

Can MF, Aktaş M ve Demirci A. Kuzey-doğu Akdeniz'in Derin Sularında Bulunan Plesionika martia (A.Milne-Edwards, 1883) (Decapoda: Pandalidae )'nın Populasyon Yap1s1 ve Verimliliği Üzerine Bir Ön Çalışma. E.U. Journal of Fisheries \& Aquatic Sciences. 2006; 23 (1/3): 365-367.

Chang O, Ceuk WL, Nikelson R, Martin $\mathbf{R}$ and Finne G. İndole in Shrimp Effect of Fresh Storage Temperature Freezing and Boiling. Journal of Food Science. 1983; 48: 813-816.

Erdem ME ve Bilgin S. Pişmiş ve çiğ olarak buzdolab1 sicaklığında muhafaza edilen karides (Palaemon adspersus Rathke, 1837)'in kalitesinde meydana gelen değişimler üzerine araștırmalar. F.Ü. Fen ve Mühendislik Bilimleri Dergisi. 2004; 16(4), 687-694.

Frangos L, Pyrgotou N, Giatrakou V, Ntzimani $A$ and Savvaidis IN. Combined effects of salting, oregano oil and vacuum-packaging on the shelf-life of refrigerated trout fillets. Food Microbiology. 
2010; 27 (1) :115-121.

Fernandez-Lopez j, Zhi N, Aleson-Carbonell I, Perez-Alvarez, A, Kuri V. Antioxidant and antibacterial activities of natural extract, application in beef meatballs. Meat Sci. 2005; 69 (3),371-380.

Huss HH. Fresh Fish: Quality and Quality Changes. Rome: Food and Agriculture Organization (FAO) of the United Nations. 1988; 132p.

Karaman S, Digrak M, Ravid U and Ilçim A. Antibacterial and antifungal activty of the essential oils of Thymus revolutus Celak from Turkey. Journal of Ethnopharmacology. 2001; 76:183-86.

Kocataş A, Katağan T, Sezgin M, Kırkım F and Koçak C. Crustacean Diversity of the Cystoseira Facies in the Aegean Coast of Turkey. Turk. J. Zool. 2004; 28: 309-316.

Kykkidou S, Giatrakou V, Papavergou A, Kontominas M.G and Savvaidis IN. Effect of thyme essential oil and packaging treatments on fresh Mediterranean swordfish fillets during storage at $4^{\circ} \mathrm{C}$. Food Chemistry. 2009;115 (1): 169-175.

Lambert RJW, Skandamis PN, Coote $\mathbf{P}$ and Nychas GE. A study of the minimum inhibitory concentration and mode of action of oregano essential oil, thymol and carvacrol. Journal of Applied Microbiology. 2001; (91): 453-462p.

Lee SY and Jin $\mathbf{H H}$. Inhibitory activity of natural antimicrobial compounds alone or in combination with nisin against Enterobacter sakazakii. The Society for Applied Microbiology, Letters in Applied Microbiology. 2008; (47) :315-321.

Lean LP and Suhaila M. Antioxidative and Antimycotic effect of turmeric, lemon-grass, Betel leaves, Clove, Black Papper Leaves and Garcinia Atriviridis on butter cakes. Journal of the Science of Food and Agriculture. 1999; 79 (13): 1817-1822.

Mastromatteo M. Alessandra Danza., Amalia Conte., Giuseppeuratore and Matteo Alessandro Del Nobile. Shelf life of ready to use peeled shrimps as affected by thymol essential oil and modified atmosphere packaging. InternationalJournal, of, FoodMicrobiology. 2010; (144): 250-256.

Matches O.R. Effects of temperature on the decomposition of pacific coast shrimp (Pandelus jordani). J. of Food Sci. 1982; 47:1044-1047.
Neuman R, Molar P, and Arnold S. SensorischeLebensmitteluntersuchung. Veb Fachbuchverlag. Leipzig. 1985; 29 (2): pp 152

Şentürk A. Bazı Değerlendirilmiş Kabuklu Su ürünlerinin Mikrobiyolojik özellikleri üzerine Olan Faktörlerin Araştırılması. T.C.Tarım Köyişleri Bakanlığı Tarımsal Araştırmalar Genel Müdürlüğü. Genel Yayın No:20. Ankara, 1994.

Santos L.D, James C and Teutscher F. Guidelines for, Chilled, Fish, Storage Experiments. FAO Fisheries Technical Paper. 1981; 210p.

Shamshad SI, Kher-un-N, and Riaz M. Shelf life of shrimp (Penaeus merguiensis) stored at different temperatures (Document). Journal of Food Science. 1990a; 55 (5) 12011205.

Shamshad SI, Nisa KU, Riaz M, Zuberi R and Quarri RB. Shelf Life of Shrimp (Penaeus merguiensis) Stored at Different Temperatures. Journal of Food Science. 1990b; 55: 1201-1205.

Stockemer J and Nieper L. Parameter zur Beurteilung der Verderbs von NordseeKrabben (Crangon crangon). Archiv fur Lebensmittel hygiene. 1984; (35): 1- 24

Ünlüsayın M. ve Gülyavuz H. Su Ürünleri İşleme Teknolojisi. Akdeniz Üniversitesi Su Ürünleri Fakültesi Ders Kitabi. Antalya.. 2008.

Varlık C, Uğur M, Gökoğlu N ve Gün H. Su Ürünlerinde Kalite Kontrol İlke ve Yöntemleri. Gıda Teknolojisi Derneği Yayın No: 17. İstanbul. 1993a.; 174s.

Varlık C ve Gökoğlu N. Dondurulmuş karideslerin ( Penaeus Longirostris. 1845) Depolanmas1. E.U. Su Ürünleri Fak. Su Ürünleri Dergisi. 1993b;10: 71-81.

Varlık C, Baygar T, Özden Ö. Erkan N ve Metin S. Soğukta Depolanan Karideslerin (Parapenaeus longirostris, LUCAS 1846) Bazı Duygusal, Fiziksel ve Kimyasal Parametrelerinin Belirlenmesi. Turk J Vet Anim Sci. 2000; 24: 181-185. 